\title{
DETEKSI PENYALAHGUNAAN NARKOBA DENGAN METODE TWIN BOUNDED SVM
}

\section{Detection Of Drugs Abuse with Twin Bounded SVM Method}

\author{
Berny Pebo Tomasouw* ${ }^{* 1}$, Yopi Andry Lesnussa ${ }^{2}$ \\ 1,2 Jurusan Matematika, FMIPA, Universitas Pattimura \\ Jln. Ir. M. Putuhuna, Kampus Unpatti, Poka-Ambon, 97233, Indonesia
}

Corresponding author e-mail: 1* bptomasouw@gmail.com

\begin{abstract}
Abstrak
Twin Bounded SVM (TB-SVM) merupakan penyempurnaan dari metode Twin SVM dan memiliki keunggulan dalam masalah klasifikasi dibandingkan SVM standar. Dalam penelitian ini, metode TBSVM linier dan TB-SVM nonlinier akan diterapkan untuk mendeteksi penggunaan narkoba berdasarkan 23 gejala yang dialami. Data pelatihan dan pengujian dibagi ke dalam tiga skema pembagian data (skema 60/40, skema 70/30 dan skema 80/20) dengan tujuan untuk mengetahui tingkat akurasi terbaik yang bisa diperoleh. Hasil pengujian menunjukkan bahwa TB-SVM nonlinier dengn kernel RBF memiliki tingkat akurasi lebih baik dibandingkan dengan TB-SVM linier yakni 80\% pada skema $60 / 40,90 \%$ pada skema 70/30, dan $95 \%$ pada skema 80/20.
\end{abstract}

Kata Kunci : Twin bounded, SVM, narkoba, deteksi.

\begin{abstract}
Twin Bounded SVM (TB-SVM) is an improvement of the Twin SVM method and has advantages in classification problems compared to standard SVM. In this research, linear TB-SVM and nonlinear TBSVM methods will be applied to detect drug use based on 23 symptoms experienced. The training and testing data is divided into three partition data schemes (60/40 scheme, 70/30 scheme and 80/20 scheme) in order to determine the best level of accuracy that can be obtained. The test results show that the nonlinear TB-SVM with the RBF kernel has a better accuracy rate than the linear TB-SVM, that is $80 \%$ at 60/40 scheme, $90 \%$ at 70/30 scheme, and $95 \%$ at $80 / 20$ scheme.
\end{abstract}

Keywords: Twin bounded, SVM, drugs, detection 


\section{PENDAHULUAN}

Narkoba adalah singkatan narkotika, psikotropika dan bahan adiktif lain. Narkotika merupakan salah satu obat, bahan atau zat yang jika masuk tubuh berpengaruh pada fungsi tubuh, terutama otak. Pemakaian dan peredaran narkotika dan psikotropika diawasi secara ketat dengan Undang-Undang, yaitu UndangUndang Nomor 35 tahun 2009 tentang Narkotika. Kepemilikan, pemakaian serta peredaran narkotika dan psikotropika secara tidak sah merupakan pelanggaran hukum [1]. Pada tahun 2013 Badan Narkotika Nasional (BNN) mencatat jumlah penyalahgunaan narkoba di Indonesia mencapai empat juta. Sebesar 70 persen dari jumlah tersebut adalah pengguna dari golongan pekerja, sementara 22 persen merupakan kelompok pelajar atau mahasiswa, serta delapan persen pengangguran dan lainnya[2]. Pemerintah dan seluruh masyarakat bersama-sama melakukan upaya untuk melakukan pencegahan penyalahgunaan narkoba serta pemberantasan peredarannya.

Salah satu upaya tersebut yaitu membangun fasilitas rehabilitasi atau terapi medis bagi para penyalahgunaan narkoba. Sebelum rehabilitasi, para penyalahguna melakukan serangkaian tes untuk dapat mengetahui jenis narkoba apa yang digunakan. Tes yang dapat dilakukan yaitu tes biologis seperti mendeteksi melalui urin, darah, rambut, keringat dan lain-lain. Akan tetapi karena kendala waktu, maka biaya serta fasilitas yang minim di beberapa daerah membuat pendeteksian seseorang menderita narkoba menjadi terhambat [2]. Oleh karena itu perlu dilakukan penelitian untuk mendekteksi penggunaan narkoba dengan pendekatan konsep Machine Learning dalam hal ini metode Support Vector Machine (SVM) yang akan mengklasifikasikan seseorang positif menggunakan narkoba berdasarkan gejala-gejala yang dialami.

Dalam [3] dijelaskan bahwa Konsep dasar SVM bermula dari masalah klasifikasi dua kelas yang tergolong dalam masalah linier (linear problem). SVM berusaha menemukan hyperplane (pemisah) terbaik pada input space untuk memisahkan dua kelas tersebut. Selanjutnya SVM dikembangkan agar dapat bekerja pada masalah non-linear, dengan memasukkan konsep kernel pada ruang kerja berdimensi tinggi. Dalam mencari hyperplane terbaik, SVM akan dihadapkan pada proses mencari solusi dari masalah pemrograman kuadratik. Penelitian [4], [5], [6], [7] dan [8] memperlihatkan bahwa SVM memiliki hasil yang lebih baik dalam masalah klasifikasi.

Selanjutnya, Jayadeva dkk [9] dalam penelitiannya berhasil mengembangkan variasi SVM yang baru dan diberi nama Twin Support Vector Machines (T-SVM). Berbeda dengan konsep dasar SVM yang berusaha menemukan sebuah hyperplane terbaik untuk memisahkan dua kelas, T-SVM mencoba menemukan dua hyperplane optimal untuk memisahkan dua kelas tersebut. Jayadeva juga memperlihatkan bahwa dari segi waktu perhitungan dan keakurasian klasifikasi, T-SVM lebih unggul dibandingkan SVM standar. Selain itu, T-SVM juga diterapkan dalam berbagai masalah antara lain pengenalan suara, pembelajaran multi-label, klasifikasi penyakit Alzheimer, dan deteksi kanker pancreas [10][11][12][13]. Shao, dkk [14] menyempurnakan hasil penelitian Jayadeva dan menghasilkan variasi T-SVM yang lain yaitu Twin Bounded Support Vector Machines (TB-SVM).

Penelitian terkait yang sebelumnya dilakukan oleh Pangrestu dan Widiastuti [2] dengan judul "Pembangunan Sistem Pendeteksi Penyalahgunaan Narkoba Menggunakan Algoritma Jaringan Syaraf Tiruan Metode Backpropagation" serta R. Dasmasela, dkk[15] dengan judul Penerapan Metode Support Vector Machine (SVM) untuk Mendeteksi Penyalahgunaan Narkoba. Sedangkan dalam penelitian ini akan digunakan metode TB-SVM untuk mendeteksi penyalahgunaan narkoba berdasarkan gejala-gejala yang dialami.

\section{METODE PENELITIAN}

Data yang digunakan dalam penelitian ini adalah data 101 orang pasien rawat jalan yang diperoleh dari Badan Narkotika Nasional Provinsi Maluku dan disertai dengan 23 jenis gejala yang dialami. Gejala-gejala tersebut akan dijadikan sebagai variabel input dalam metode TB-SVM dan secara lengkap dapat dilihat pada Tabel 1, berikut: 
Tabel 1. Variabel dalam data input

\begin{tabular}{clcclc}
\hline No. & \multicolumn{1}{c}{ Gejala } & Inisialisasi & No. & \multicolumn{1}{c}{ Gejala } & Inisialisasi \\
\hline 1 & Mudah tersinggung & $x_{1}$ & 13 & Mental terganggu & $x_{13}$ \\
\hline 2 & Kecanduan & $x_{2}$ & 14 & Sembelit & $x_{14}$ \\
\hline 3 & Depresi & $x_{3}$ & 15 & Nafsu makan hilang & $x_{15}$ \\
\hline 4 & Agitasi & $x_{4}$ & 16 & Keracunan & $x_{16}$ \\
\hline 5 & Insomnia & $x_{5}$ & 17 & Paranoid & $x_{17}$ \\
\hline 6 & Kerusakan Ginjal & $x_{6}$ & 18 & Susunan syaraf pusat rusak & $x_{18}$ \\
\hline 7 & Gangguan Seks & $x_{7}$ & 19 & Mudah gugup & $x_{19}$ \\
\hline 8 & Paru-paru terganggu & $x_{8}$ & 20 & Pusing & $x_{20}$ \\
\hline 9 & Mudah lelah & $x_{9}$ & 21 & Detak jantung meningkat & $x_{21}$ \\
\hline 10 & Muntah & $x_{10}$ & 22 & Otot melemah & $x_{22}$ \\
\hline 11 & Berkeringat & $x_{11}$ & 23 & Susah buang air kecil & $x_{23}$ \\
\hline 12 & Gelisah & $x_{12}$ & & & \\
\hline
\end{tabular}

Sedangkan, berdasarkan jenis narkoba pada data maka ditetapkan 4 kelas yang dipakai sebagai target yakni kelas 1: sabu, kelas 2 : ganja, kelas 3 : lem, dan kelas 4 : sintesis. Selanjutnya, 101 data tersebut akan akan dibagi menjadi dua bagian yakni data pelatihan dan data pengujian dengan beberapa skema pembagian seperti pada tabel berikut.

Tabel 2. Skema Pembagian Data

\begin{tabular}{ccc}
\hline No & Skema Pembagian & Keterangan \\
\hline \multirow{2}{*}{1} & $60 / 40$ & $\begin{array}{l}61 \text { data pelatihan } \\
40 \text { data pengujian }\end{array}$ \\
\hline \multirow{2}{*}{2} & \multirow{2}{*}{$70 / 30$} & $\begin{array}{l}71 \text { data pelatihan } \\
30 \text { data pengujian }\end{array}$ \\
\multirow{2}{*}{3} & \multirow{2}{*}{$80 / 20$} & $\begin{array}{l}81 \text { data pelatihan } \\
20 \text { data pengujian }\end{array}$ \\
\hline
\end{tabular}

\subsection{TB-SVM Linier}

Misalkan matriks $A \in \square^{m_{1} \times n}$ mewakili sampel data dari kelas +1 dan matriks $B \in \square^{m_{2} \times n}$ mewakili sampel data dari kelas -1. Sedangkan $e_{1} \in \square^{m_{1} \times 1}$ dan $e_{2} \in \square^{m_{2} \times 1}$ adalah vektor kolom yang semua elemennya bernilai satu. Twin Bounded SVM linier bertujuan untuk mencari dua fungsi pemisah (hyperplane) yang optimal, yakni

$$
f_{1}(x)=x w_{1}+b_{1}=0 \text { dan } f_{2}(x)=x w_{2}+b_{2}=0
$$

dimana $w_{1}, w_{1} \in \square^{n \times 1}$ adalah parameter bobot dan $b_{1}, b_{2} \in \square$ adalah parameter bias.

Parameter bobot dan bias di atas dapat diperoleh dengan menyelesaikan dua masalah pemrograman kuadratik berikut:

$$
\operatorname{Max}_{\alpha} e_{2}^{T} \alpha-\frac{1}{2} \alpha^{T} G\left(H^{T} H+c_{3} I\right)^{-1} G^{T} \alpha
$$

dengan kendala $0 \leq \alpha \leq c_{1}$

dan

$$
\operatorname{Max}_{\gamma} e_{1}^{T} \gamma-\frac{1}{2} \gamma^{T} H\left(G^{T} G+c_{4} I\right)^{-1} H^{T} \gamma
$$

dengan kendala $0 \leq \gamma \leq c_{2}$ 
Sedangkan sampel data $x \in \square^{n}$ yang baru diklasifikasikan ke dalam kelas $r(r=1,2)$ berdasarkan jarak yang minimum untuk kedua hyperplane yang diperoleh, yakni $r=\arg \min _{j=1,2}\left|x w_{j}+b_{j}\right|$

$$
\text { Kelas } r=\arg \min _{j=1,2}\left|x w_{j}+b_{j}\right|
$$

Secara lengkap, algoritma TB-SVM linier adalah sebagai berikut :

i. Bentuk matriks $H=\left[\begin{array}{ll}A & e_{1}\end{array}\right]$ dan $G=\left[\begin{array}{ll}B & e_{2}\end{array}\right]$.

ii. Tentukan nilai parameter $c_{1}, c_{2}, c_{3}$, dan $c_{4}$.

iii. Dapatkan solusi dari pemrograman kuadratik (2) dan (3) yang berupa nilai $\alpha$ dan $\gamma$.

iv. Dapatkan parameter $w_{1}, w_{2}, b_{1}$, dan $b_{2}$ dengan menggunakan persamaan

$$
\left[\begin{array}{l}
w_{1} \\
b_{1}
\end{array}\right]=-\left(H^{T} H+c_{3} I\right)^{-1} G^{T} \alpha
$$

dan

$$
\left[\begin{array}{l}
w_{2} \\
b_{2}
\end{array}\right]=\left(G^{T} G+c_{4} I\right)^{-1} H^{T} \gamma
$$

v. Gunakan Persamaan (4) untuk penentuan keanggotaan kelas.

\subsection{TB -SVM Nonlinier}

Untuk mengatasi masalah klasifikasi nonlinier maka perlu digunakan metode kernel. Dua hyperplane yang akan dihasilkan dengan metode kernel adalah

$$
K(x, C) u_{1}+b_{1}=0 \text { dan } K(x, C) u_{2}+b_{2}=0
$$

dimana $K$ adalah kernel yang dipilih dan $C=\left[\begin{array}{l}A \\ B\end{array}\right]$. Sedangkan dua masalah pemrograman kuadratik yang harus diselesaikan adalah

$$
\operatorname{Max}_{\alpha} e_{2}^{T} \alpha-\frac{1}{2} \alpha^{T} S\left(R^{T} R+c_{3} I\right)^{-1} S^{T} \alpha
$$

dengan kendala $0 \leq \alpha \leq c_{1}$.

dan

$$
\operatorname{Max}_{\gamma} e_{1}^{T} \gamma-\frac{1}{2} \gamma^{T} R\left(S^{T} S+c_{4} I\right)^{-1} R^{T} \gamma
$$

dengan kendala $0 \leq \gamma \leq c_{2}$.

Selanjutnya, sampel data $x \in \square^{n}$ yang baru diklasifikasikan ke dalam kelas $r(r=1,2)$ berdasarkan jarak yang minimum untuk kedua hyperplane tersebut, yakni

$$
\text { Kelas } r=\arg \min _{j=1,2}\left|K(x, C) u_{j}+b_{j}\right|
$$

Secara lengkap, algoritma TB-SVM nonlinier adalah sebagai berikut :

i. Bentuk matrik $R=\left[K(A, C) e_{1}\right]$ dan $S=\left[\begin{array}{lll}K(B, C) & e_{2}\end{array}\right]$.

ii. Tentukan nilai parameter $c_{1}, c_{2}, c_{3}$, dan $c_{4}$.

iii. Dapatkan solusi dari pemrograman kuadratik (6) dan (7) yang berupa nilai $\alpha$ dan $\gamma$.

iv. Dapatkan parameter $u_{1}, u_{2}, b_{1}$, dan $b_{2}$ dengan menggunakan persamaan

$$
\left[\begin{array}{l}
u_{1} \\
b_{1}
\end{array}\right]=-\left(R^{T} R+c_{3} I\right)^{-1} S^{T} \alpha
$$


dan

$$
\left[\begin{array}{l}
u_{2} \\
b_{2}
\end{array}\right]=\left(S^{T} S+c_{4} I\right)^{-1} R^{T} \gamma
$$

v. Gunakan Persamaan (8) untuk penentuan keanggotaan kelas.

\section{HASIL DAN PEMBAHASAN}

Data 101 pasien yang telah dibagi kedalam beberapa skema data pelatihan dan data pengujian, akan diproses menggunakan metode TB-SVM linier maupun TB-SVM non linier sehingga bisa diketahui tingkat akurasi terbaik. Sedangkan nilai parameter-parameter yang digunakan dalam pemograman kuadratik untuk mendapatkan hyperplane yang optimal dapat dilihat pada Tabel 3, berikut:

Tabel 3. Parameter-parameter untuk pemograman kuadratik

\begin{tabular}{cccc}
\hline$c_{1}$ & $c_{2}$ & $c_{3}$ & $c_{4}$ \\
\hline 1000 & 1000 & 0.4 & 3 \\
\hline
\end{tabular}

\subsection{Hasil Pengujian dengan Metode TB-SVM Linier}

Hasil Pengolahan dan pengujian data menggunakan Support Vektor Machine linier untuk ketiga skema pembagian data dapat dilihat pada Tabel 4, berikut:

Tabel 4. Tingkat Akurasi Dengan Metode SVM Linier

\begin{tabular}{ccc}
\hline No. & Skema Pembagian & Tingkat Akurasi \\
\hline 1 & $60 / 40$ & $80 \%$ \\
\hline 2 & $70 / 30$ & $83.3 \%$ \\
\hline 3 & $80 / 20$ & $80 \%$ \\
\hline
\end{tabular}

Dari Tabel 4 terlihat bahwa tingkat akurasi terbaik diperoleh pada skema pembagian data 70/30 sebesar $83.3 \%$.

\subsection{Hasil Pengujian dengan Metode TB-SVM Nonlinier}

Untuk metode TB-SVM nonlinier, akan digunakan dua buah kernel sebagai pembanding yakni kernel polinomial dan kernel RBF (Radial Basis Function). Nilai parameter yang akan dibuat bervariasi pada kernel polinomial adalah nilai $d$ (pangkat) sedangkan pada kernel RBF adalah nilai $\gamma$ (sigma). Hal ini bertujuan untuk mengetahui tingkat akurasi yang terbaik. Hasil pengolahan dan pengujian data menggunakan SVM nonlinier untuk ketiga skema pembagian data dapat dilihat pada Tabel 5, Tabel 6 dan Tabel 7 berikut ini.

Tabel 5. Tingkat Akurasi dengan Skema Pembagian Data 60/40

\begin{tabular}{|c|c|c|c|c|c|c|c|c|c|c|}
\hline \multicolumn{11}{|c|}{ Jenis Kernel : Polinomial } \\
\hline $\begin{array}{l}\text { Parameter } \\
\text { Kernel }(d)\end{array}$ & 2 & 3 & 4 & 5 & 6 & 7 & 8 & 10 & 15 & 20 \\
\hline $\begin{array}{l}\text { Tingkat } \\
\text { Akurasi (\%) }\end{array}$ & 80 & 77.5 & 77.5 & 77.5 & 80 & 80 & 80 & 77.5 & 75 & 75 \\
\hline \multicolumn{11}{|c|}{ Jenis Kernel : RBF } \\
\hline $\begin{array}{l}\text { Parameter } \\
\text { Kernel }(\gamma)\end{array}$ & 0.01 & 0.1 & 1.5 & 2 & 2.5 & 3 & 3.5 & 4 & 4.5 & 5 \\
\hline $\begin{array}{l}\text { Tingkat } \\
\text { Akurasi (\%) }\end{array}$ & 80 & 77.5 & 82.5 & 85 & 85 & 85 & 85 & 82.5 & 82.5 & 80 \\
\hline
\end{tabular}

Dari Tabel 5 terlihat bahwa hasil pengujian dengan kernel polinomial memperoleh hasil terbaik pada nilai parameter $d=2, d=6, d=7$ dan $d=8$ dengan tingkat akurasi sebesar $80 \%$, sedangkan untuk kernel RBF diperoleh tingkat akurasi sebesar $85 \%$ pada $\gamma=2, \gamma=2.5, \gamma=3$, dan $\gamma=3.5$. 
Tabel 6. Tingkat Akurasi dengan Skema Pembagian Data 70/30

\begin{tabular}{|c|c|c|c|c|c|c|c|c|c|c|}
\hline \multicolumn{11}{|c|}{ Jenis Kernel : Polinomial } \\
\hline $\begin{array}{l}\text { Parameter } \\
\text { Kernel }(d)\end{array}$ & 2 & 3 & 4 & 5 & 6 & 7 & 8 & 10 & 15 & 20 \\
\hline $\begin{array}{l}\text { Tingkat } \\
\text { Akurasi }(\%)\end{array}$ & 83.3 & 83.3 & 80 & 86.7 & 80 & 83.3 & 80 & 76.7 & 76.7 & 73.3 \\
\hline \multicolumn{11}{|c|}{ Jenis Kernel : RBF } \\
\hline $\begin{array}{l}\text { Parameter } \\
\text { Kernel }(\gamma)\end{array}$ & 0.01 & 0.1 & 1.5 & 2 & 2.5 & 3 & 3.5 & 4 & 4.5 & 5 \\
\hline $\begin{array}{l}\text { Tingkat } \\
\text { Akurasi (\%) }\end{array}$ & 80 & 77.5 & 83.3 & 86.7 & 90 & 90 & 86.7 & 86.7 & 86.7 & 86.7 \\
\hline
\end{tabular}

Dari Tabel 6 terlihat bahwa hasil pengujian dengan kernel polinomial memperoleh hasil terbaik pada nilai parameter $d=5$ dengan tingkat akurasi sebesar $86.7 \%$, sedangkan untuk kernel RBF diperoleh tingkat akurasi sebesar $90 \%$ pada $\gamma=2.5$ dan $\gamma=3$.

Tabel 7. Tingkat Akurasi dengan Skema Pembagian Data 80/20

\begin{tabular}{|c|c|c|c|c|c|c|c|c|c|c|}
\hline \multicolumn{11}{|c|}{ Jenis Kernel : Polinomial } \\
\hline $\begin{array}{l}\text { Parameter } \\
\text { Kernel }(d)\end{array}$ & 2 & 3 & 4 & 5 & 6 & 7 & 8 & 10 & 15 & 20 \\
\hline $\begin{array}{l}\text { Tingkat } \\
\text { Akurasi (\%) }\end{array}$ & 90 & 95 & 95 & 95 & 90 & 85 & 85 & 80 & 75 & 75 \\
\hline \multicolumn{11}{|c|}{ Jenis Kernel : RBF } \\
\hline $\begin{array}{l}\text { Parameter } \\
\text { Kernel }(\gamma)\end{array}$ & 0.01 & 0.1 & 1.5 & 2 & 2.5 & 3 & 3.5 & 4 & 4.5 & 5 \\
\hline $\begin{array}{l}\text { Tingkat } \\
\text { Akurasi (\%) }\end{array}$ & 90 & 90 & 95 & 95 & 95 & 95 & 95 & 95 & 95 & 95 \\
\hline
\end{tabular}

Dari Tabel 7 terlihat bahwa hasil pengujian dengan kernel polynomial memperoleh hasil terbaik pada nilai parameter $d=3, d=4$, dan $d=5$ dengan tingkat akurasi sebesar $95 \%$, sedangkan untuk kernel RBF diperoleh tingkat akurasi juga sebesar $95 \%$ pada $\gamma=1.5, \gamma=2, \gamma=2.5, \gamma=3, \gamma=3.5, \gamma=4, \gamma=4.5$ dan $\gamma=5$.

\section{KESIMPULAN}

Berdasarkan hasil penelitian dapat disimpulkan bahwa metode TB-SVM nonlinier memiliki tingkat akurasi yang lebih baik dibandingkan TB-SVM linier. Tingkat akurasi terbaik pada masing-masing skema pembagian data dengan menggunakan kernel RBF adalah 80\% pada skema $60 / 40,90 \%$ pada skema $70 / 30$, dan $95 \%$ pada skema 80/20. Secara keseleruhan, hasil ini juga masih lebih baik jika dibandingkan dengan hasil penelitian yang diperoleh pada [9]. Oleh karena itu, metode TB-SVM merupakan metode yang tepat untuk mendeteksi penyalahgunaan narkoba.

\section{DAFTAR PUSTAKA}

[1] C. J. Kiaking, "Penyalahgunaan Narkotika Menurut Hukum Pidana dan Undang-Undang Nomor 35 Tahun 2009 Tentang Narkotika", LEX CRIMEN, vol.6, no.1, Januari 2017

[2] D. P. Pangrestu dan N. Indriani Widiastuti, "Pembangunan Sistem Pendeteksi Penyalahgunaan Narkoba Menggunakan Algoritma Jaringan Syaraf Tiruan Metode Backpropagation", Jurnal Ilmiah Komputer dan Informatika (KOMPUTA), vol.3, no.1, pp27-23, Maret 2014

[3] B. P. Tomasouw dan M. I. Irawan, "Multiclass Twin Bounded Support Vector Machine Untuk Pengenalan Ucapan", Seminar Nasional Penelitian, Pendidikan dan Penerapan MIPA, pp.49-58, 2 Juni, 2012

[4] M. Bhasin dan G. P. S. Raghava, "Prediction of CTL epitopes using QM, SVM and ANN techniques", Vaccine Journal, vol.22, no.23, pp3195-3204, Agustus 2004

[5] W. T. Wong dan S. H. Hsu, "Application of SVM and ANN for image retrieval”, European Journal of Operational Research, vol.173, no.3, pp. 938-950, September 2006 
[6] I. Hmeidi, B. Hawashin, dan E. El-Qawasmeh, "Performance of KNN and SVM classifiers on full word Arabic articles", Advanced Engineering Informatics, vol.22, no.1, pp106-111, Januari 2008

[7] Yushan Qiu, "Towards Prediction of Pancreatic Cancer Using SVM Study Model”, JSM Clinical Oncology And Research, vol2. No.4, Mei 2014

[8] I. T. Utami, "Perbandingan Kinerja Klasifikasi Support Vector Machine (SVM) Dan Regresi Logistik Biner dalam Mengklasifikasikan Ketepatan Waktu Kelulusan Mahasiswa FMIPA UNTAD”, Jurnal Ilmiah Matematika dan Terapan, vol.15, no.2, pp256-267, Desember 2018

[9] Jayadeva, R. Khemchandani, and Suresh Chandra, "Twin Support Vector Machines for Pattern Classification", IEEE:Transactions on Pattern Analysis and Machine Intelligence, vol.29, no.5, pp 905-910, Mei 2007.

[10] C. Yang and Z. Wu. Study to multi-twin support vector machines and its applications in speaker recognition" in Proc. International Conference On Computational Intelligence And Software Engineering 2009, pp1-4, Dec. 11-13, 2009

[11] W-J. Chen, dkk, "MLTSVM: a novel twin support vector machine to multi-label learning", Elsevier : Pattern Recognition, vol. 52, pp.61-74, Oktober 2015

[12] S. Alam, dkk, "Twin SVM-Based Classification of Alzheimer's Disease Using Complex Dual-Tree Wavelet Principal Coefficients and LDA", Journal of Healthcare Engineering, vol.2017, pp1-12, Agustus 2017

[13] W. Sadewo, dkk, "Pancreatic Cancer Early Detection Using Twin Support Vector Machine Based on Kernel", Symmetry, vol.12, no.4, April 2020

[14] Y. Shao, C. Zhang, X. Wang, and N. Deng, "Improvements on Twin Support Vector Machines”, IEEE Transactions on Neural Networks, vol.22, no.6, Mei 2011

[15] R. Dasmasela, B. P. Tomasouw, dan Z. A. Leleury, "Penerapan Metode Support Vector Machine (SVM) Untuk Mendeteksi Penyalahgunaan Narkoba", PARAMETER : JURNAL MATEMATIKA, STATISTIKA DAN TERAPANNYA, vol.1, no.2, pp93101, Mei 2021 
